Article

\title{
Evaluation of A Concentrated Preterm Formula as a Liquid Human Milk Fortifier in Preterm Babies at Increased Risk of Feed Intolerance
}

\author{
Anish Pillai ${ }^{1,2}{ }^{\circ}$, Susan Albersheim ${ }^{1,2}$, Julie Matheson ${ }^{3}$, Vikki Lalari ${ }^{1}$, Sylvia Wei ${ }^{3}$, \\ Sheila M Innis ${ }^{2,+}$ and Rajavel Elango $2,3,4, *$ \\ 1 Neonatal-Perinatal Medicine, British Columbia Women's and Children's Hospital, University of British \\ Columbia, Vancouver, BC V6H 3N1, Canada; anish.pillai@cw.bc.ca (A.P.); salbersheim@cw.bc.ca (S.A.); \\ vlalari@cw.bc.ca (V.L.) \\ 2 Department of Pediatrics, University of British Columbia, Vancouver, BC V5Z 3V4 Canada; \\ Sinnis@bcchr.ubc.ca \\ 3 British Columbia Children's Hospital Research Institute (BCCHRI), Vancouver, BC V5Z 4H4 Canada; \\ jmatheson@bchr.ca (J.M.); sylviaawei@gmail.com (S.W.) \\ 4 School of Population and Public Health, University of British Columbia, Vancouver, BC V6T 1Z3 Canada \\ * Correspondence: relango@bcchr.ubc.ca; Tel.: +1-604-875-2000 (ext. 4911) \\ + Deceased on 10 February 2016.
}

Received: 28 August 2018; Accepted: 2 October 2018; Published: 4 October 2018

check for updates

\begin{abstract}
There are concerns around safety and tolerance of powder human milk fortifiers to optimize nutrition in preterm infants. The purpose of this study was to evaluate the tolerance and safety of a concentrated preterm formula (CPF) as a liquid human milk fortifier (HMF) for premature infants at increased risk of feeding intolerance. We prospectively enrolled preterm infants over an 18-month period, for whom a clinical decision had been made to add CPF to human milk due to concerns regarding tolerance of powder HMF. Data on feed tolerance, anthropometry, and serum biochemistry values were recorded. Serious adverse events, such as mortality, necrotizing enterocolitis (NEC), and sepsis, were monitored. A total of 29 babies received CPF fortified milk during the study period. The most common indication for starting CPF was previous intolerance to powder HMF. Feeding intolerance was noted in 4 infants on CPF. The growth velocity of infants was satisfactory $(15.9 \mathrm{~g} / \mathrm{kg} /$ day) after addition of CPF to feeds. The use of CPF as a fortifier in preterm babies considered at increased risk for feed intolerance seems well tolerated and facilitates adequate growth. Under close nutrition monitoring, this provides an additional option for human milk fortification in this challenging subgroup of preterm babies, especially in settings with limited human milk fortifier options.
\end{abstract}

Keywords: premature; formula; fortification; human milk

\section{Introduction}

Human milk is considered the ideal food for neonates and is the preferred choice of diet for preterm and very low birth weight infants [1-3]. The benefits of human milk for preterm infants include a lower risk of necrotizing enterocolitis (NEC) and severe infections, improved feed tolerance, improved cognition and development, and shorter hospital stay [4-7]. These benefits are probably related to the multiple growth factors, immunological constituents, and bioactive factors in human milk that are absent from infant formula. However, preterm breast milk is deficient in certain nutrients and does not meet the nutritional requirements of a premature baby $[2,8,9]$. Feeding premature babies with 
unfortified human milk is associated with poor growth rate, reduced bone mineral density, and poorer short-term developmental outcome [10-12].

Human milk fortifier (HMF) is an additive designed to boost the total energy, protein, and micronutrient content of human milk to enhance growth in preterm infants [13]. The key benefits of fortification are improved short-term growth, bone mineralization, and protein status. However, there have been concerns regarding an increased risk of feed intolerance and NEC in preterm babies on HMF [14-18]. Additives can increase the osmolality of milk, which has been associated with mucosal injury and reduced gut motility [19-22]. It thus becomes challenging to add nutritional supplements to feeds in a baby with a history of intolerance to HMF or prior NEC and achieve adequate growth.

Human milk fortifiers are available in different compositions, specifically varying in protein (source and amounts), micronutrient composition, and form (powder or liquid). The use of a liquid product might be preferred over powder in the Neonatal Intensive Care Unit (NICU) setting to reduce risk of contamination and infection [23]. Our NICU routinely uses a commercially available powder HMF preparation; however, there have been concerns among clinicians regarding the tolerance of a powdered fortifier in premature babies with a previous history of NEC, surgical bowel, or feed intolerance. In our NICU, preterm infants who are postsurgical for intestinal problems are considered at increased risk for development of intestinal calculi (milk curd syndrome) when powder HMF is added to their feeds [24]. The intestinal concretions of powder HMF may be significant enough to cause acute deterioration and warrant surgical intervention due to intestinal obstruction [24-26]. Unlike powdered products, liquid HMF has the advantage of sterility and easier mixing with human milk. Liquid fortifiers also provide an additional option for feeding preterm infants whose mothers have insufficient milk supply to fulfil the infant's needs, since the use of a liquid fortifier both extends the volume of milk and decreases the need for using powder HMF.

The use of powder HMF is standard practice in our NICU and liquid HMF is not available for use in preterm babies. Health Canada approved Similac Special Care 30 (SSC30) concentrated preterm formula (CPF) for use in premature babies in NICUs in Canada in early 2014. CPF can be used as a high calorie standalone feed or mixed with less concentrated preterm formulas to achieve desired caloric density. Although there is limited literature on the use of SSC30 (CPF) as a liquid human milk fortifier in the NICU [27], there is no experience or data in the subgroup of preterm babies at increased risk for feed intolerance. At the time of this study, there were no other liquid human milk fortifier products available in Canada. The primary objective of this project was to assess the post-marketing safety and tolerance of $\mathrm{CPF}$ as a liquid human milk fortifier in a special group of premature babies considered at increased risk for feed intolerance. The secondary objectives were to describe the short-term outcomes, including growth, serum chemistries, and morbidities with CPF use. This cohort comprised mainly babies with previous intolerance to powder HMF or babies with intestinal perforation/NEC, for whom the clinical team did not feel comfortable in adding or restarting powder HMF.

\section{Materials and Methods}

Study population/setting: The study was conducted in a 60 bed tertiary care NICU at BC Women's Hospital and Health Centre, in Vancouver, British Columbia. The unit cares for approximately 670 babies per year, admitted from across British Columbia and the Yukon Territory. Babies for whom a clinical decision had been made to add CPF as a liquid nutrient fortifier to mother's own milk (MOM) or pasteurized donor human milk (DHM) provided by BC Women's Provincial Milk Bank, located within the hospital, were eligible for the study. All babies who received CPF during the 18-month enrolment period were included. The clinical decision to start CPF was made if there was significant intolerance after adding powder HMF or if the clinical team felt the baby would not be a good candidate for powder products. The potential benefit of CPF in this cohort could be due to its lower osmolality, easier solubility, and non-acidified nature. However, it must be noted that the powder HMF used in our cohort was also non-acidified, and the small difference in osmolality may 
not have clinical significance. The composition of CPF in comparison to powder HMF is provided in Table 1.

Table 1. Comparison of powder human milk fortifier (HMF) and concentrated preterm formula (CPF).

\begin{tabular}{|c|c|c|}
\hline \multicolumn{3}{|c|}{24 kcal/oz Fortified Preterm Human Milk* } \\
\hline Per $100 \mathrm{~mL}$ & Powder HMF & $\mathrm{CPF}$ \\
\hline Dilution/Mixing & 4 packets to $100 \mathrm{~mL} \mathrm{HM}$ & $40 \mathrm{~mL} \mathrm{CPF}$ with $60 \mathrm{~mL} \mathrm{HM}$ \\
\hline Calories & 81 & 81 \\
\hline Protein & 2.6 & 2.1 \\
\hline Iron & 1.48 & 0.74 \\
\hline $\mathrm{Ca}$ & 119 & 90.6 \\
\hline $\mathbf{P}$ & 59.3 & 46 \\
\hline Vitamin D & 154 & 63 \\
\hline Osmolality & 325 & 304 \\
\hline
\end{tabular}

Exclusion criteria were infants with congenital/chromosomal anomalies, and multiorgan or intestinal dysfunction that in the opinion of the infant's primary physician was not compatible with survival or attainment of full enteral feeds. Enteral feeding was initiated and advanced as per existing unit policy with the use of standardized powder HMF protocol initiated at $22 \mathrm{kcal} / \mathrm{oz}$ or $74 \mathrm{kcal} / 100 \mathrm{~mL}$ (2 packets per $100 \mathrm{~mL}$ ), and advanced to a target calorie content of $24 \mathrm{kcal} / \mathrm{oz}$ or $81 \mathrm{kcal} / 100 \mathrm{~mL}$ (4 packets per $100 \mathrm{~mL}$ ). If a decision was made to start CPF for any baby, fortification would be initiated at $10 \%$ of CPF, mixed with $90 \%$ of human milk ( $1: 9$ ratio giving $21 \mathrm{kcal} / \mathrm{oz}$ ) and increased gradually by $10 \%$ each day, as tolerated. The typical target fortification would be $40 \% \mathrm{CPF}$ with $60 \%$ human milk, to achieve a calorie content of $24 \mathrm{kcal} / \mathrm{oz}$. However, if poor growth was noted, there was an option of increasing fortification to $25 \mathrm{kcal} / \mathrm{oz}$ with 50\% CPF and 50\% human milk, as per manufacturer recommendations. The babies were closely monitored by the dietitian and clinical team for nutritional adequacy.

Study design: This was a prospective observational cohort study conducted over an 18-month period from September 2014 to February 2016. Data recording for this study was performed in a predetermined, consistent format; data were extracted prospectively and confirmed retrospectively from the infants' health records, and entered into an electronic database. Research approval was obtained from the University of British Columbia / Children's and Women's Health Centre of British Columbia Research Ethics Board (\# H14-01452). The study did not involve changes to clinical practice or collection of additional blood samples. Since the addition of CPF displaces human milk from feeds, it was not considered ethically appropriate to do a randomized trial or have a control group. Hence, in this observational study, we only included babies for whom a clinical decision to add CPF was made by the medical team.

The primary outcome variable was feed intolerance, which was defined as feeds being withheld for $24 \mathrm{~h}$ or more due to concerns related to feeding. This included clinical features like abdominal distension, emesis, and change in stools/stoma output. Other outcome variables recorded were growth velocity (GV), presence of major morbidities such as NEC, late onset neonatal sepsis (LONS), chronic lung disease (CLD), retinopathy of prematurity (ROP), metabolic bone disease (MBD), and abnormal serum chemistry.

Blood was drawn initially as ordered by the clinical team for specific biochemistries or hematology until the infant was stable and growing with enteral feeds. Subsequently, biweekly samples were analysed for hematocrit, ionized calcium, alkaline phosphatase, phosphorus, albumin, prealbumin, blood urea nitrogen (BUN), sodium, and potassium. Blood gas was drawn as clinically indicated. 
Additional information collected included data regarding total fluid intake, parenteral nutrition and enteral feeds.

Infants were weighed daily and head circumference $(\mathrm{HC})$ and length $(\mathrm{cm})$ were recorded weekly, as per unit policy. Fenton growth curve percentile rankings, with $\mathrm{Z}$ scores, were plotted for all anthropometric measurements, enabling us to account for differences in gestational age using the revised 2013 Fenton growth charts [31-33]. Growth velocity (GV) was calculated using the exponential model for each infant as GV $=[1000 \times \ln (W n / W 1)] /\left(D n-D_{1}\right)$ where $\mathrm{W}$ is the weight and $\mathrm{D}$ is the day. This exponential model has been shown to be more consistent and is validated for use in very low birth weight (VLBW) infants $[34,35]$. Length was measured as centimeters $(\mathrm{cm})$ and length gain was calculated as $\mathrm{cm} /$ day. Similar calculations were used for growth in head circumference. Growth was calculated for the total NICU stay as well as specifically for the period the babies were on CPF fortified milk.

Data for major morbidities including NEC, LONS, CLD, ROP, and MBD, were collected each week from the medical charts for each infant receiving CPF. Confirmed NEC was defined as $\geq$ Stage 2 by the Modified Bell's staging criteria [36]. Infants who required therapy with oxygen $>21 \%$ for at least 28 days were classified as having CLD at 36 weeks postmenstrual age using National Institutes of Health (NIH) consensus definition. [37]. Diagnosis of ROP and staging were categorized according to international classification for ROP or need for intervention (laser, Avastin therapy, or surgery) [38]. Babies with alkaline phosphatase levels greater than $500 \mathrm{IU} / \mathrm{L}$ were diagnosed as MBD as per our unit policy [39]

\section{Results}

Study population: A total of 29 patients received SSC 30 as fortifier during the study period. (Figure 1) Data from all infants were used to analyse the fortifier tolerance; however, only data from 23 babies who received SSC 30 fortifier for a minimum of 14 days were utilized for growth assessment. Due to the limited sample size, the data are described as median and interquartile ranges (IQR). 


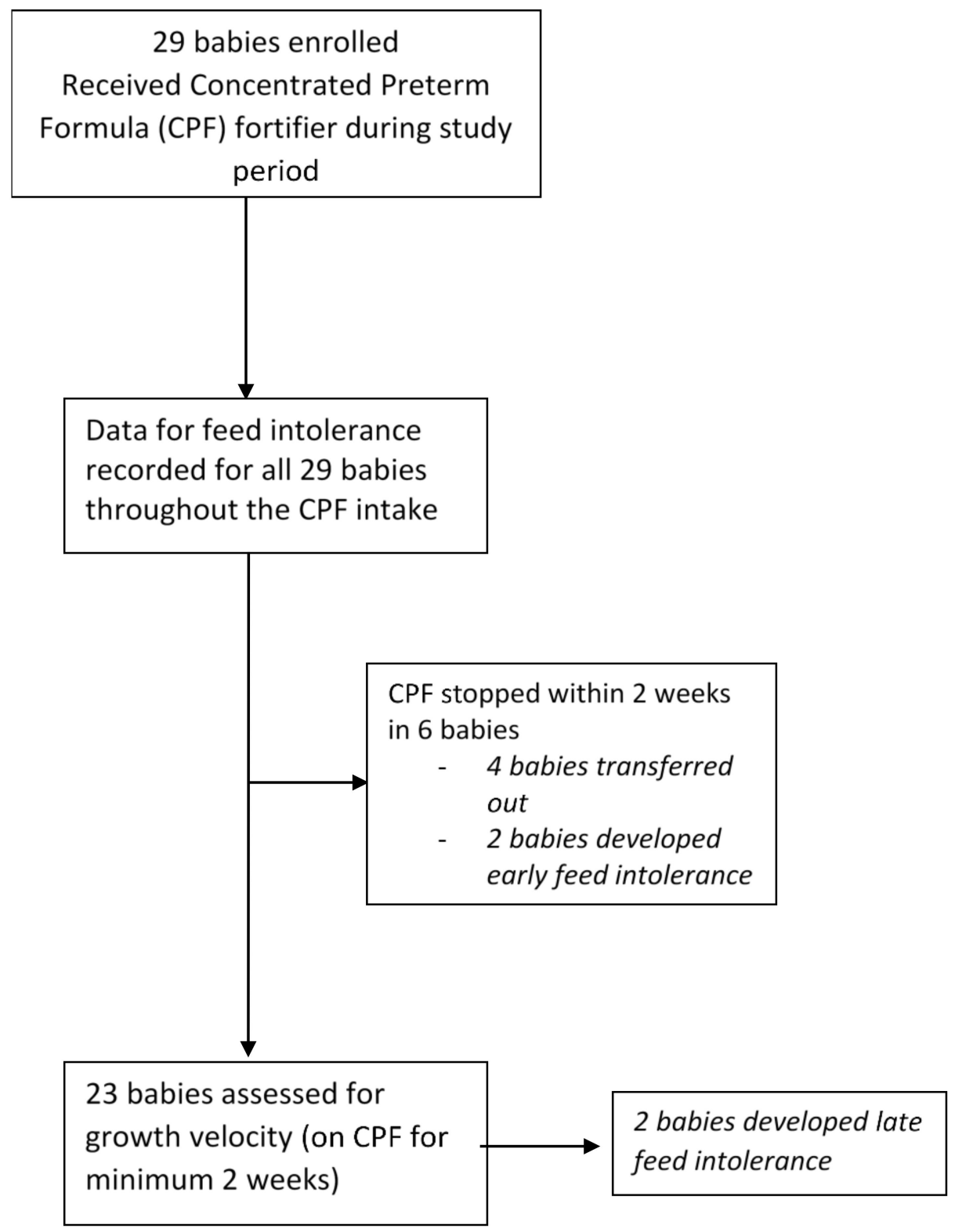

Figure 1. Flowchart of study participants.

Patient Characteristics: The baseline characteristics and morbidities of the study population are described below (Table 2). The median day of life for achieving full feeds was 30 days, which suggests that the study cohort comprised 'slow feeders' due to intestinal problems or evidence of feed intolerance. The addition of CPF was done at a median age of 47 days, as many babies were initially started on powder HMF. The total duration on CPF supplementation was variable.

Indication to start CPF: Addition of CPF as a fortifier to feeds was done only for cases where the clinical team did not feel comfortable using powder HMF. Since the use of powder HMF was standard practice in our NICU, the most common indication for use of CPF fortifier was intolerance to powder $\operatorname{HMF}(n=12,41 \%)$. Indicators of intolerance to powder HMF included nil per oral status (NPO) for at least $24 \mathrm{~h}$ due to concerns related to feeding. The use of CPF due to surgical bowel was identified in 7 babies (24\%), with NEC being the reason in 5 cases, and spontaneous intestinal perforation in 2 infants. The overall incidence of surgical NEC in our cohort was $17 \%(n=5) ; 3$ cases reported after powder HMF, none after CPF. This was much higher than the overall NEC incidence rate in our unit of $1.8 \%$ for the year 2015. Of all surgical babies, 3 were managed with a Penrose drain and 4 required 
a stoma. None of the neonates met the criteria for short bowel syndrome. In 8 babies (28\%), CPF was started as the initial fortifier of choice due to concerns regarding potential tolerance of powder HMF by the medical team. This included babies who were slow to reach full feeds and showed signs of intolerance during various stages of feed advancement. In two babies (twins), the decision to add CPF was made with the dual intention of enhancement of volume for low breast milk production and a history of intolerance to powder HMF.

Table 2. Patient characteristics.

\begin{tabular}{|c|c|}
\hline$n=29$ & Value \\
\hline Gestation age, week + day; median (IQR) & $26+3(24+6-28+2)$ \\
\hline Birth weight, g; median (IQR) & $833(635-1050)$ \\
\hline Male sex; $n(\%)$ & $20(68.9 \%)$ \\
\hline C section; $n(\%)$ & $20(68.9 \%)$ \\
\hline Enteral feeds start day; median (IQR) & $2(2-5)$ \\
\hline Day of life when full feeds achieved; median (IQR) & $30(16-53)$ \\
\hline TPN days; median (IQR) & $29(17-61)$ \\
\hline CPF start day; median (IQR) & $47(31-60)$ \\
\hline Number of days CPF received; median (IQR) & $28(13-39)$ \\
\hline Retinopathy of Prematurity (ROP) needing treatment *; $n(\%)$ & $6(20.6 \%)$ \\
\hline Chronic Lung Disease (CLD); $n(\%)$ & $18(62.1 \%)$ \\
\hline Late onset sepsis (blood) $\$$ & $10(34.5 \%)$ \\
\hline Metabolic bone disease & $13(44.8 \%)$ \\
\hline Discharge/Transfer gestation week; median (IQR) & $39(36-44)$ \\
\hline Discharge/Transfer weight g; median (IQR) & 2795 (2300-3907) \\
\hline
\end{tabular}

${ }^{*}$ ROP requiring laser therapy, Avastin, or surgery ${ }^{\$}$ Blood culture positive cases.

Tolerance: The overall incidence of feed intolerance (NPO for greater than $24 \mathrm{~h}$ ) in the study cohort was $14 \%(n=4)$. (Table 3 ) In one baby, the intolerance symptoms after starting CPF were thought to be unrelated to the CPF fortifier itself, and CPF was restarted after a few days with feeds. There was one case of culture positive sepsis (late onset sepsis) after being on CPF for 28 days. Two babies had ventilator associated pneumonia (clinical sepsis), requiring antibiotic therapy. None of the babies had NEC (clinical or radiologic) after addition of CPF.

Table 3. Characteristics of babies developing any feed intolerance.

\begin{tabular}{|c|c|c|c|c|c|c|c|c|c|}
\hline Baby & $\mathrm{GA}^{*}$ & $\begin{array}{c}\text { Birth } \\
\text { Weight (g) }\end{array}$ & $\begin{array}{c}\text { Day of } \\
\text { Start of } \\
\text { CPF }\end{array}$ & $\begin{array}{c}\text { Days on CPF } \\
\text { When Intolerance } \\
\text { Noted }\end{array}$ & $\begin{array}{l}\text { Abdominal } \\
\text { Distension }\end{array}$ & Emesis & $\begin{array}{c}\text { Change in } \\
\text { Stool/Stoma } \\
\text { Output }\end{array}$ & $\begin{array}{l}\text { Clinical/Culture } \\
\text { Positive Sepsis }\end{array}$ & $\begin{array}{l}\text { If Restarted } \\
\text { on CPF }\end{array}$ \\
\hline A & $27+1$ & 1000 & 58 & 2 & No & Yes & No & Clinical & No \\
\hline B & $24+0$ & 840 & 47 & 10 & No & No & Yes & No & No \\
\hline C & $28+0$ & 574 & 40 & 21 & Yes & No & No & Clinical & Yes \\
\hline $\mathrm{D}$ & $29+6$ & 1135 & 29 & 28 & Yes & No & No & Culture & No \\
\hline
\end{tabular}

Growth: The study cohort received CPF for a variable period during their NICU stay. The median number of days required to reach from start of CPF to the recommended concentration of $24 \mathrm{kcal} / \mathrm{oz}$ was 7 (5-9.5). After the addition of CPF fortifier at $24 \mathrm{kcal} / \mathrm{oz}$, the GV of neonates (calculated by exponential model) improved from median $12.5 \mathrm{~g} / \mathrm{kg} /$ day to median $15.9 \mathrm{~g} / \mathrm{kg} /$ day. Median weight gain calculated as grams/day during this period on CPF was also within acceptable range (31.4 g/day). Of the 7 surgical babies, 4 babies had bowel resection and stoma placement and were followed by the intestinal rehabilitation team. The weight gain on CPF for this cohort was $18.5 \mathrm{~g} /$ day. Some babies $(n=10)$ received additional protein or lipid additives along with CPF, as decided by the medical team. However, the GV was satisfactory $(16.8 \mathrm{~g} / \mathrm{kg} /$ day) even for the cohort receiving CPF as the only fortifier and no additional supplements $(n=13)$. The overall growth in head circumference and length remained satisfactory with the addition of CPF fortifier. (Table 4) 
Table 4. Growth and laboratory data on CPF ( $n=23$, unless specified otherwise).

\begin{tabular}{cc}
\hline Characteristic & Value \\
\hline Total observation days on CPF median (IQR) & $34(24-49)$ \\
Days on CPF 24 kcal/oz median (IQR) & $27(12.5-35.5)$ \\
Growth velocity prior to CPF $(\mathrm{g} / \mathrm{kg} /$ day) median (IQR) & $12.53(11.0-15.4)$ \\
Growth velocity on CPF $(\mathrm{g} / \mathrm{kg} /$ day) median (IQR) & $15.87(11.7-19.0)$ \\
Weight at start of CPF (grams) median (IQR) & $1500(1254-1746)$ \\
Weight at end of CPF (grams) median (IQR) & $2128(2500-2778)$ \\
Weight gain on CPF $(\mathrm{g} /$ day) median (IQR) & $31.4(22.9-36.2)$ \\
Head growth prior to CPF $(n=13) \mathrm{cm} /$ week median $(\mathrm{IQR})$ & $0.75(0.53-0.76)$ \\
Head growth on CPF $(n=13) \mathrm{cm} /$ week median $(\mathrm{IQR})$ & $0.79(0.69-0.86)$ \\
Length growth prior to CPF $(n=12) \mathrm{cm} /$ week median $(\mathrm{IQR})$ & $0.88(0.84-0.93)$ \\
Length growth on CPF $(n=12) \mathrm{cm} /$ week median $(\mathrm{IQR})$ & $0.77(0.67-1.08)$ \\
Maximum BUN $(n=27) \mathrm{mmol} / \mathrm{L}$ median $(\mathrm{IQR})$ & $2.4(1.25-4)$ \\
Maximum pre-albumin $(n=27) \mathrm{mg} / \mathrm{L}$ median $(\mathrm{IQR})$ & $103(73.5-119.5)$ \\
\hline
\end{tabular}

Chemistry: One baby had elevated phosphate $(2.54 \mathrm{mmol} / \mathrm{L})$ and 2 babies had hyponatremia (both $128 \mathrm{mmol} / \mathrm{L}$ ) on CPF. No abnormalities of ionized calcium or potassium were noted. The median value for urea increased from 0.9 to $2.7 \mathrm{mmol} / \mathrm{L}$ and the median pre-albumin levels improved from 66 to $103 \mathrm{mg} / \mathrm{L}$ on CPF fortified feeds. None of the neonates had alkaline phosphatase levels greater than $500 \mathrm{IU} / \mathrm{L}$ after starting $\mathrm{CPF}$, and the median alkaline phosphatase values showed a downward trend from a median of $363 \mathrm{IU} / \mathrm{L}$ at the start of CPF to $245 \mathrm{IU} / \mathrm{L}$ at the end of CPF. No infant had metabolic acidosis while on CPF feeds.

\section{Discussion}

The reason for evaluating CPF as a human milk liquid fortification product in situations where there was reluctance by the clinical team to use powder HMF was the potential advantage of a liquid product in mixing and lower osmolality without compromising growth outcomes. In our unit, the clinical team (surgical and medical) did not wish to start (or restart) powder HMF in a certain group of neonates due to our previous experience of intestinal obstruction in high-risk babies on powder HMF [24]. Since Health Canada did not approve any other fortifier products apart from powder $\mathrm{HMF}$ and $\mathrm{CPF}$ for use in preterm infants, we felt the need to test this alternative option for high-risk babies. Our intent was to report the experience of using this product as a liquid HMF in this cohort. Conducting a prospective randomized trial with $\mathrm{CPF}$ was not considered appropriate, as CPF displaces a significant volume of human milk. To our knowledge, this is the first report describing tolerance and outcomes of CPF as a liquid HMF in babies considered at increased risk of feed intolerance. Addition of $\mathrm{CPF}$ as a liquid fortifier displaces $40 \%$ of human milk volume, which is a disadvantage; however, the more concentrated commercial liquid bovine HMFs used in other centers [40] were not available in Canada at the time of the study. Addition of multiple products can increase the osmolality of the milk and further contribute to issues with tolerance [19]. A previous clinical trial comparing CPF to powder HMF did not show a difference in weight gain or tolerance between the two groups. They compared two nutritional products from the same manufacturer [27]. However, their study group comprised all very low birth weight (VLBW) babies compared to our cohort of babies at increased risk of feed intolerance. Feeding intolerance is a widely described outcome variable in studies involving preterm enteral nutrition [41]. The overall incidence of feed intolerance in our group was $14 \%$. However, out of the 4 babies who showed intolerance, CPF was restarted in one baby, as the medical team did not attribute the intolerance to CPF. Moreover, one baby was receiving additional protein additive at the time intolerance was noted. Kim et al. [36] conducted a randomized controlled trial comparing powder HMF versus liquid hydrolysed fortifier among preterm babies $<33$ weeks and birth weights ranging between 700-1500 g. The incidence of babies with feed intolerance in their cohort was $23 \%$ in the liquid fortifier group and $19 \%$ in the powder HMF group. A retrospective study 
by Thoene and colleagues [42] compared outcomes of babies on non-acidified liquid HMF, acidified liquid HMF, and powder HMF. Their cohort comprised bigger babies with fewer medical morbidities. Although they did not report feeding intolerance as an outcome, the incidence of NEC in the acidified liquid HMF group was 13\%, compared to nil in the powder HMF group. Mukhopadhyay et al. [43] enrolled babies $<1500 \mathrm{~g}$ and $<34$ weeks in a randomized trial, comparing powder HMF fortification and exclusive human milk feeding with vitamin and mineral supplementation. They found that the incidence of feed intolerance (vomiting, abdominal distension, and increased aspirates) was $21 \%$ in the powder HMF group and $29 \%$ in the control group. These studies report similar or higher incidence of feed intolerance than our study population, which suggests that CPF is well tolerated, especially since our population consisted of babies that were at a higher baseline-risk for feed intolerance.

There is no international consensus regarding what constitutes the ideal growth pattern for premature babies, especially those born very preterm [44]. The median GV of our study population throughout the NICU stay was $13.4 \mathrm{~g} / \mathrm{kg} /$ day. However, once feeds were fortified with CPF to $24 \mathrm{kal} / \mathrm{oz}$, the median GV improved to $15.9 \mathrm{~g} / \mathrm{kg} /$ day. In a prospective randomized trial comparing ultra-concentrated liquid HMF with powder HMF, Moya and colleagues demonstrated a mean weight gain of $15.8 \mathrm{~g} / \mathrm{kg} /$ day in the liquid HMF group. They included infants $\leq 1250 \mathrm{~g}$ and the liquid HMF used in that study provided around $20 \%$ more protein compared to powder HMF [45]. The previous clinical trial using concentrated preterm formula demonstrated that VLBW babies on CPF had a mean weight gain of $18.3 \mathrm{~g} / \mathrm{kg} /$ day compared to $16.9 \mathrm{~g} / \mathrm{kg} /$ day in the powder HMF group [27]. In the retrospective study by Thoene et al., the growth rates reported were $15.4 \mathrm{~g} / \mathrm{kg} / \mathrm{day}$ in the powder HMF group, $10.6 \mathrm{~g} / \mathrm{kg} /$ day in the acidified liquid HMF group, and $14 \mathrm{~g} / \mathrm{kg} /$ day in the non-acidified liquid HMF group, respectively [42]. There are limited data on the growth outcomes of babies at high risk of feed intolerance. A multicenter retrospective study by Hintz et al. looked at growth outcomes of babies post NEC (surgical and medical NEC). They reported a weight gain of $13 \mathrm{~g} / \mathrm{kg} / \mathrm{day}$ [46]. Although only one-fourth of babies in our group had intestinal surgery, their median growth velocity post CPF fortification was $18.9 \mathrm{~g} / \mathrm{kg} /$ day $(n=7)$. Mukhopadhyay et al. reported that the weight gain in babies on fortified human milk was $15 \mathrm{~g} / \mathrm{kg} /$ day versus $12.9 \mathrm{~g} / \mathrm{kg} /$ day in the unfortified milk group [43]. In another trial involving very low birth weight (VLBW) infants, Nicoll et al. achieved a mean weight gain of $15.1 \mathrm{~g} / \mathrm{kg} /$ day in the fortified group compared to $13.2 \mathrm{~g} / \mathrm{kg} /$ day in the unfortified group [47]. Ehrenkranz et al. have reported that with improved weight gain in hospitalized preterm infants, the incidence of neurodevelopmental impairment and need for rehospitalisation decreased significantly. A rate of weight gain $>18 \mathrm{~g} / \mathrm{kg} /$ day and an $\mathrm{HC}$ growth rate of $>0.9 \mathrm{~cm} /$ week were associated with better neurodevelopmental and growth outcomes [48]. Although the observed growth in our study population was below the optimal target, the growth velocity markedly improved after addition of CPF. Growth results in our cohort need to be interpreted with caution, as some babies received additional nutritional components (protein or lipid supplements) while on CPF, as decided by the clinical team, since the primary purpose of this study was to assess for tolerance and safety. Those babies also demonstrated similar growth and were not adversely affected by the supplements. Thus, the nutritional adequacy and tolerance of human milk fortified with CPF needs to be monitored closely by the clinical team. Depending on the feed volume, type of milk (donor or mother's milk), and growth pattern, individualized supplementation may be required after assessment by the team.

Acidification of milk has been shown to cause changes in nutritional and cellular composition [49]. Thoene et al. reported a higher incidence of metabolic acidosis and slower growth in infants receiving an acidified liquid HMF compared to those receiving powder HMF [50]. In our study, none of the babies on CPF developed metabolic acidosis or significant biochemical abnormalities. One of the reasons for not having metabolic acidosis in our cohort could be the late addition of CPF fortifier to feeds, as the acid buffering mechanisms are poor in the first few weeks of life in a preterm infant [51].

Our study has a few limitations, including the lack of a control group, small sample size, and some missing weekly data on length and head circumference. The strengths of our study include its prospective design and inclusion of preterm babies with previous history of feed or HMF intolerance 
and babies with surgical bowel. While the issue of displacement of volume of human milk due to a liquid fortifier could be considered a disadvantage, depending on whether sufficient mother's milk is available, this can be an advantage in selective cases.

\section{Conclusions}

The use of CPF formula as a liquid fortifier in preterm babies at increased risk for feed intolerance appears to be well tolerated and facilitates growth. In a center with limited liquid human milk fortification options, CPF provided an additional/useful alternative for this challenging subgroup of preterm babies. However, we recommend using CPF with close monitoring of growth and biochemical parameters to ensure nutritional adequacy.

Author Contributions: S.M.I. and S.A. conceptualized the study. V.L., S.W., and J.M. performed data collection and measurements. R.E. and S.A. were involved in planning and supervised the work. A.P., R.E., and S.A. processed the study data and performed the data analysis. A.P. drafted the initial manuscript and designed the figures. R.E. and S.A. aided in interpreting the results and edited the manuscript.

Funding: This research was supported by Abbott Nutrition Division, Quebec, Canada; grant number [ANCA1401].

Acknowledgments: The authors wish to acknowledge Roger A Dyer, Research Manager, Innis Lab for administrative support.

Conflicts of Interest: The authors declare no conflict of interest. The funders had no role in the design of the study; in the collection, analyses, or interpretation of data; in the writing of the manuscript, and in the decision to publish the results.

\section{References}

1. Agostoni, C.; Buonocore, G.; Carnielli, V.P.; De Curtis, M.; Darmaun, D.; Decsi, T.; Domellöf, M.; Embleton, N.D.; Fusch, C.; et al. Enteral nutrient supply for preterm infants: Commentary from the European Society of Paediatric Gastroenterology, Hepatology and Nutrition Committee on Nutrition. J. Pediatr. Gastroenterol. Nutr. 2010, 50, 85-91. [CrossRef] [PubMed]

2. Eidelman, A.I. Breastfeeding and the use of human milk: An analysis of the American Academy of Pediatrics 2012 Breastfeeding Policy Statement. Breastfeed Med. 2012, 7, 323-324. [CrossRef] [PubMed]

3. ESPGHAN Committee on Nutrition; Agostoni, C.; Braegger, C.; Decsi, T.; Kolacek, S.; Koletzko, B.; Michaelsen, K.F.; Mihatsch, W.; Moreno, L.A.; Puntis, J.; et al. Breast-feeding: A commentary by the ESPGHAN Committee on Nutrition. J. Pediatr. Gastroenterol. Nutr. 2009, 49, 112-125. [CrossRef] [PubMed]

4. Lucas, A.; Cole, T.J. Breast milk and neonatal necrotising enterocolitis. Lancet 1990, 336, 1519-1523. [CrossRef]

5. Lucas, A.; Morley, R.; Cole, T.J.; Lister, G.; Leeson-Payne, C. Breast milk and subsequent intelligence quotient in children born preterm. Lancet 1992, 339, 261-264. [CrossRef]

6. McGuire, W.; Anthony, M.Y. Donor human milk versus formula for preventing necrotising enterocolitis in preterm infants: Systematic review. Arch. Dis. Child. Fetal Neonatal Ed. 2003, 88, 11-14. [CrossRef]

7. Sisk, P.M.; Lovelady, C.A.; Dillard, R.G.; Gruber, K.J.; O'Shea, T.M. Early human milk feeding is associated with a lower risk of necrotizing enterocolitis in very low birth weight infants. J Perinatol. 2007, 27, 428-433. [CrossRef] [PubMed]

8. Bauer, J.; Gerss, J. Longitudinal analysis of macronutrients and minerals in human milk produced by mothers of preterm infants. Clin. Nutr. 2011, 30, 215-220. [CrossRef] [PubMed]

9. Arslanoglu, S.; Moro, G.E.; Ziegler, E.E.; The Wapm Working Group on Nutrition, null. Optimization of human milk fortification for preterm infants: New concepts and recommendations. J. Perinat. Med. 2010, 38, 233-238. [CrossRef] [PubMed]

10. Hawthorne, K.M.; Abrams, S.A. Safety and efficacy of human milk fortification for very-low-birthweight infants. Nutr. Rev. 2004, 62, 482-485. [CrossRef] [PubMed]

11. Kuschel, C.A.; Harding, J.E. Multicomponent fortified human milk for promoting growth in preterm infants. Cochrane. Database Syst. Rev. 2004. [CrossRef]

12. Maggio, L.; Costa, S.; Gallini, F. Human milk fortifiers in very low birth weight infants. Early Hum. Dev. 2009, 85, S59-S61. [CrossRef] [PubMed] 
13. Brown, J.V.E.; Embleton, N.D.; Harding, J.E.; McGuire, W. Multi-nutrient fortification of human milk for preterm infants. Cochrane. Database Syst. Rev. 2016. [CrossRef] [PubMed]

14. Schanler, R.J. Suitability of human milk for the low-birthweight infant. Clin. Perinatol. 1995, 22, $207-222$. [CrossRef]

15. Schanler, R.J.; Abrams, S.A. Postnatal attainment of intrauterine macromineral accretion rates in low birth weight infants fed fortified human milk. J. Pediatr. 1995, 126, 441-447. [CrossRef]

16. Arslanoglu, S.; Bertino, E.; Coscia, A.; Tonetto, P.; Giuliani, F.; Moro, G.E. Update of adjustable fortification regimen for preterm infants: A new protocol. J. Biol. Regul. Homeost. Agents 2012, 26, 65-67. [PubMed]

17. Arslanoglu, S.; Moro, G.E.; Ziegler, E.E. Adjustable fortification of human milk fed to preterm infants: Does it make a difference? J. Perinatol. 2006, 26, 614-621. [CrossRef] [PubMed]

18. Sullivan, S.; Schanler, R.J.; Kim, J.H.; Patel, A.L.; Trawöger, R.; Kiechl-Kohlendorfer, U.; Chan, G.M.; Blanco, C.L.; Abrams, S.; Cotten, C.M.; et al. An exclusively human milk-based diet is associated with a lower rate of necrotizing enterocolitis than a diet of human milk and bovine milk-based products. J. Pediatr. 2010, 156, 562-567. [CrossRef] [PubMed]

19. Pearson, F.; Johnson, M.J.; Leaf, A.A. Milk osmolality: Does it matter? Arch. Dis. Child. Fetal Neonatal Ed. 2013, 98, 166-169. [CrossRef] [PubMed]

20. Goldblum, O.M.; Holzman, I.R.; Fisher, S.E. Intragastric feeding in the neonatal dog. Its effect on intestinal osmolality. Am. J. Dis. Child. 1981, 135, 631-633. [CrossRef] [PubMed]

21. Schmid, H.R.; Ehrlein, H.J. Effects of enteral infusion of hypertonic saline and nutrients on canine jejunal motor patterns. Dig. Dis. Sci. 1993, 38, 1062-1072. [CrossRef] [PubMed]

22. Srinivasan, L.; Bokiniec, R.; King, C.; Weaver, G.; Edwards, A.D. Increased osmolality of breast milk with therapeutic additives. Arch. Dis. Child. Fetal Neonatal Ed. 2004, 89, F514-F517. [CrossRef] [PubMed]

23. Palcich, G.; de Moraes Gillio, C.; Aragon-Alegro, L.C.; Pagotto, F.J.; Farber, J.M.; Landgraf, M.; Destro, M.T. Enterobacter sakazakii in dried infant formulas and milk kitchens of maternity wards in São Paulo, Brazil. J. Food Prot. 2009, 72, 37-42. [CrossRef] [PubMed]

24. Stanger, J.; Zwicker, K.; Albersheim, S.; Murphy, J.J. Human milk fortifier: An occult cause of bowel obstruction in extremely premature neonates. J. Pediatr. Surg. 2014, 49, 724-726. [CrossRef] [PubMed]

25. Flikweert, E.R.; La Hei, E.R.; De Rijke, Y.B.; Van de Ven, K. Return of the milk curd syndrome. Pediatr. Surg. Int. 2003, 19, 628-631. [CrossRef] [PubMed]

26. Murase, M.; Miyazawa, T.; Taki, M.; Sakurai, M.; Miura, F.; Mizuno, K.; Itabashi, K.; Toki, A. Development of fatty acid calcium stone ileus after initiation of human milk fortifier. Pediatr. Int. 2013, 55, 114-116. [CrossRef] [PubMed]

27. Willeitner, A.; Anderson, M.; Lewis, J. Highly Concentrated Preterm Formula as an Alternative to Powdered Human Milk Fortifier: A Randomized Controlled Trial. J. Pediatr. Gastroenterol. Nutr. 2017, 65, 574-578. [CrossRef] [PubMed]

28. Tsang, R.C.; Uauy, R.; Koletzko, B.; Zlotkin, S. Nutrition of the Preterm Infant: Scientific Basis and Practical Guidelines; Digital Educational Publishing, Inc.: Cincinnati, OH, USA, 2005.

29. Boyce, C.; Watson, M.; Lazidis, G.; Reeve, S.; Dods, K.; Simmer, K.; McLeod, G. Preterm human milk composition: A systematic literature review. Br. J. Nutr. 2016, 116, 1033-1045. [CrossRef] [PubMed]

30. Gidrewicz, D.A.; Fenton, T.R. A systematic review and meta-analysis of the nutrient content of preterm and term breast milk. BMC Pediatr. 2014, 14, 216. [CrossRef] [PubMed]

31. Fenton, T.R. A new growth chart for preterm babies: Babson and Benda's chart updated with recent data and a new format. BMC Pediatr 2003, 3, 13. [CrossRef] [PubMed]

32. Fenton, T.R.; Kim, J.H. A systematic review and meta-analysis to revise the Fenton growth chart for preterm infants. BMC Pediatr. 2013, 13, 59. [CrossRef] [PubMed]

33. Fenton, T.R.; Sauve, R.S. Using the LMS method to calculate z-scores for the Fenton preterm infant growth chart. Eur. J. Clin. Nutr. 2007, 61, 1380-1385. [CrossRef] [PubMed]

34. Patel, A.L.; Engstrom, J.L.; Meier, P.P.; Kimura, R.E. Accuracy of methods for calculating postnatal growth velocity for extremely low birth weight infants. Pediatrics 2005, 116, 1466-1473. [CrossRef] [PubMed]

35. Patel, A.L.; Engstrom, J.L.; Meier, P.P.; Jegier, B.J.; Kimura, R.E. Calculating postnatal growth velocity in very low birth weight (VLBW) premature infants. J. Perinatol. 2009, 29, 618-622. [CrossRef] [PubMed] 
36. Bell, M.J.; Ternberg, J.L.; Feigin, R.D.; Keating, J.P.; Marshall, R.; Barton, L.; Brotherton, T. Neonatal necrotizing enterocolitis. Therapeutic decisions based upon clinical staging. Ann. Surg. 1978, 187, 1-7. [CrossRef] [PubMed]

37. Ehrenkranz, R.A.; Walsh, M.C.; Vohr, B.R.; Jobe, A.H.; Wright, L.L.; Fanaroff, A.A.; Wrage, L.A.; Poole, K. National Institutes of Child Health and Human Development Neonatal Research Network Validation of the National Institutes of Health consensus definition of bronchopulmonary dysplasia. Pediatrics 2005, 116, 1353-1360. [CrossRef] [PubMed]

38. International Committee for the Classification of Retinopathy of Prematurity The International Classification of Retinopathy of Prematurity revisited. Arch. Ophthalmol. 2005, 123, 991-999. [CrossRef] [PubMed]

39. Abdallah, E.A.A.; Said, R.N.; Mosallam, D.S.; Moawad, E.M.I.; Kamal, N.M.; Fathallah, M.G.E.-D. Serial serum alkaline phosphatase as an early biomarker for osteopenia of prematurity. Medicine (Baltimore) 2016, 95, e4837. [CrossRef] [PubMed]

40. Kim, J.H.; Chan, G.; Schanler, R.; Groh-Wargo, S.; Bloom, B.; Dimmit, R.; Williams, L.; Baggs, G.; Barrett-Reis, B. Growth and tolerance of preterm infants fed a new extensively hydrolyzed liquid human milk fortifier. J. Pediatr. Gastroenterol. Nutr. 2015, 61, 665-671. [CrossRef] [PubMed]

41. Fanaro, S. Feeding intolerance in the preterm infant. Early Hum. Dev. 2013, 89 (Suppl. 2), S13-S20. [CrossRef]

42. Thoene, M.; Lyden, E.; Weishaar, K.; Elliott, E.; Wu, R.; White, K.; Timm, H.; Anderson-Berry, A. Comparison of a powdered, acidified liquid, and non-acidified liquid human milk fortifier on clinical outcomes in premature infants. Nutrients 2016, 8, 451. [CrossRef] [PubMed]

43. Mukhopadhyay, K.; Narnag, A.; Mahajan, R. Effect of human milk fortification in appropriate for gestation and small for gestation preterm babies: A randomized controlled trial. Indian Pediatr. 2007, 44, 286-290. [PubMed]

44. Villar, J.; Giuliani, F.; Barros, F.; Roggero, P.; Coronado Zarco, I.A.; Rego, M.A.S.; Ochieng, R.; Gianni, M.L.; Rao, S.; Lambert, A.; et al. Monitoring the postnatal growth of preterm infants: A paradigm change. Pediatrics 2018, 141. [CrossRef] [PubMed]

45. Moya, F.; Sisk, P.M.; Walsh, K.R.; Berseth, C.L. A new liquid human milk fortifier and linear growth in preterm infants. Pediatrics 2012, 130, e928-e935. [CrossRef] [PubMed]

46. Hintz, S.R.; Kendrick, D.E.; Stoll, B.J.; Vohr, B.R.; Fanaroff, A.A.; Donovan, E.F.; Poole, W.K.; Blakely, M.L.; Wright, L.; Higgins, R.; et al. Neurodevelopmental and growth outcomes of extremely low birth weight infants after necrotizing enterocolitis. Pediatrics 2005, 115, 696-703. [CrossRef] [PubMed]

47. Nicholl, R.M.; Gamsu, H.R. Changes in growth and metabolism in very low birthweight infants fed with fortified breast milk. Acta. Paediatr. 1999, 88, 1056-1061. [CrossRef] [PubMed]

48. Ehrenkranz, R.A.; Dusick, A.M.; Vohr, B.R.; Wright, L.L.; Wrage, L.A.; Poole, W.K. Growth in the neonatal intensive care unit influences neurodevelopmental and growth outcomes of extremely low birth weight infants. Pediatrics 2006, 117, 1253-1261. [CrossRef] [PubMed]

49. Erickson, T.; Gill, G.; Chan, G.M. The effects of acidification on human milk's cellular and nutritional content. J. Perinatol. 2013, 33, 371-373. [CrossRef] [PubMed]

50. Thoene, M.; Hanson, C.; Lyden, E.; Dugick, L.; Ruybal, L.; Anderson-Berry, A. Comparison of the effect of two human milk fortifiers on clinical outcomes in premature infants. Nutrients 2014, 6, 261-275. [CrossRef] [PubMed]

51. Manz, F.; Kalhoff, H.; Remer, T. Renal acid excretion in early infancy. Pediatr. Nephrol. 1997, 11, $231-243$. [CrossRef] [PubMed]

(C) 2018 by the authors. Licensee MDPI, Basel, Switzerland. This article is an open access article distributed under the terms and conditions of the Creative Commons Attribution (CC BY) license (http://creativecommons.org/licenses/by/4.0/). 